\title{
A ATUAÇÃO DE ALMIRANTE E PIXINGUINHA NA CONDUÇÃO DO PROGRAMA RADIOFÔNICO O PESSOAL DA VELHA GUARDA (1947-1952): ESCOLHA DE REPERTÓRIO E ARRANJOS PARA ORQUESTRA POPULAR
}

THE WORK OF ALMIRANTE AND PIXINGUINHA CONDUCTING THERADIO PROGRAMO PESSOALDA VELHA GUARDA (19471952): CHOICE OF REPERTOIRE AND ARRANGEMENTS FOR THE POPULAR ORCHESTRA

\author{
Ana Lúcia Fontenele \\ Universidade Federal do Acre \\ alfontenele@gmail.com
}

\section{Resumo}

O presente artigo aborda a atuação de Almirante e Pixinguinha na condução do repertório e dos arranjos realizados por Pixinguinha para a orquestra popular do programa radiofônico $\bigcirc$ Pessoal da Velha Guarda. $\bigcirc$ programa tinha como objetivo divulgar estilos musicais não veiculados pela mídia da década de 1940, época em que outros estilos musicais despontavam, alguns deles com grande influência da música estrangeira, como o bolero e o samba-canção. Alguns pesquisadores da música popular no Brasil da época, como também intelectuais e compositores, manifestavam-se com relação a tal fato, como também buscavam formas de divulgar o repertório de músicas consideras por eles como de "raiz", como também a música folclórica de várias regiões do Brasil. $\bigcirc$ cantor e produtor radiofônico Almirante, juntamente com os músicos que integravam a equipe de alguns de seus programas das décadas de 1930 e 1940, como os programas Curiosidade Musicais e Orquestras e Músicos do Brasil, concentraram-se na concepção e efetivação do programa $O$ Pessoal da Velha Guarda, que foi transmitido na Rádio Tupi do Rio de Janeiro, no período de 1947 a 1952. No palco desse programa 
de auditório exibiam-se músicos e cantores que integravam um grupo regional de choro e a orquestra popular liderada por Pixinguinha.

Palavras-chaves: música popular; choro; arranjo; rádio.

\section{Abstract}

This article discusses the performance of Almirante and Pixinguinha conducting the repertoire and the arrangements made by Pixinguinha for the popular orchestra of the radio program O Pessoal da Velha Guarda. The program aimed to disseminate musical styles not conveyed by the media in the 1940s, when other musical styles emerged, some of them influenced by foreign music, such as bolero and samba-canção. Some researchers of the popular music in Brazil at the time, as well as intellectuals and composers, expressed themselves about it, but also looked for ways to promote the repertoire of songs considered by them as "root", as well as the folkloric music of several regions of Brazil. The singer and radio producer Almirante, together with the musicians who were part of the staff of some of his programs from the 1930s and 1940s, such as Curiosidade Musicais and Orquestras e Musicos do Brasil focused on the design and implementation of the program $O$ Pessoal da Velha Guarda, which was broadcast on Radio Tupi, of Rio de Janeiro, from 1947 to 1952. On the stage of this program, there were musicians and singers part of a regional group of choro and the popular orchestra, led by Pixinguinha.

Keywords: popular music; choro; arrangement; radio.

\section{Introdução}

A atuação de Almirante como pesquisador revela-se a partir da produção e apresentação de programas radiofônicos "voltados para a história (e a exaltação) de música popular urbana" (ARACÃO, 2013 , p. 20), nos quais defendia um resgate da brasilidade musical. Segundo Lima (2014, p. 23) através da sua atuação como produtor 
e apresentador de programas radiofônicos, a partir de 1938, Almirante realiza "um discurso fundador acerca da história da música popular brasileira. Esta 'historiografia' é singular sobretudo porque foi desenvolvida e difundida nos meios de comunicação de massa".

Segundo Paes (2012, p. 30-31), com a produção do programa Histórias das orquestras e dos músicos do Brasil no ano anterior ao programa $\bigcirc$ Pessoal da Velha Guarda, em 1946, Almirante inicia a empreitada de "resgate" do passado musical relativo à música popular urbana no Brasil. Segundo a autora, Almirante amplia o material que constituiu o seu acervo pessoal com o intuito de "lançar um dicionário de informações biográficas de músicos e compositores brasileiros, elaborado a partir do recolhimento preenchido por músicos de várias regiões do Brasil" e com a colaboração dos ouvintes por meio do "envio de material biográfico, sugestões de repertório e partituras".

Esse senso de organização o ajudou a produzir seus programas radiofônicos para os quais realizava pesquisas nas bibliografias de autores como Sílvio Romero, Melo Morais Filho, Renato de Almeida, Afonso Arinos e Câmara Cascudo, entre outros. Além das pesquisas em fontes bibliográficas, Almirante contava com a colaboração dos pesquisadores citados acima, processo que se inicia desde a época do programa Curiosidades Musicais, em 1938, quando Almirante recebe todo o acervo do folclorista Melo Morais como doação por parte da sua familia (PAES, 2012). Inicialmente, o Curiosidades Musicais foi um quadro apresentado por Almirante durante o Programa Casé em 1934 (LIMA, 2014). À essa época, segundo Cabral (1996), Almirante e Pixinguinha integravam a equipe do referido programa.

A partir das catalogações dos materiais recolhidos como scripts dos programas radiofônicos e as supracitadas informações enviadas pelos ouvintes (partituras, fotos e cartas), Almirante começa a construir o seu acervo que posteriormente levaria para o Museu da Imagem e do Som do Rio de Janeiro, em 1965, onde trabalhou até 1980, ano de sua morte. Tais materiais, em sintonia com os assuntos veiculados nos seus programas, consistiam em documentos relativos ao folclore e suas temáticas ligadas a cultura popular - envolvendo a música -, e a história da música popular urbana no Rio de Janeiro, tanto de épocas anteriores como contemporâneas. 
Com relação a atuação de Almirante como produtor de programas radiofônico, Vinci de Moraes afirma:

sua trajetória no rádio e formulações sobre música popular não eram tão lineares. Na prática suas atividades radiofônicas ultrapassavam a simples noção de rádio educativa e desenvolveu-se voltada nitidamente ao entretenimento. E sua percepção de cultura nacional era bastante ampla, já que não estabelecia fronteiras nítidas e rígidas entre a cultura popular tradicional, urbana e de entretenimento (MORAES, 2010, p. 239-240).

Segundo Garcia Canclini (2015, p. 22), esse tipo de dinâmica ligada ao contexto da modernização "redimensiona a arte e o folclore, o saber acadêmico e a cultura industrializada, sob condições relativamente semelhantes". Para o autor (p. 23), se antes "o folclorista e o antropólogo relacionavam o artesanato a uma matriz mítica ou a um sistema sociocultural autônomos", na atualidade "essas operações se revelam quase sempre construções culturais multicondicionadas por agentes que transcendem o artístico ou o simbólico".

Em tese de doutorado a ser defendida em março de 2018, abordamos a hipótese segundo a qual, apesar dos diversos diálogos com gêneros musicais variados, como por exemplo o jazz, na fase em que esteve produzindo arranjos de cunho comercial, Pixinguinha revisita, principalmente na fase madura da sua carreira, o tipo de musicalidade praticada no Brasil desde o final do século XIX e início do século XX (FONTENELE, 2016). Nessa perspectiva, parte dos arranjos realizados por Pixinguinha para orquestra popular no programa $\bigcirc$ Pessoal da Velha Guarda, tanto de composições próprias como para músicas de compositores do princípio do choro, encontram-se nessa tendência estético-musical.

Desde as primeiras décadas de sua atuação como músico, compositor e arranjador, Pixinguinha pôde demonstrar, em seus arranjos para os diversos grupos instrumentais dos quais liderou, o legado musical da época do princípio do choro e das bandas militares, além de incorporar características musicais da música estrangeira. Isso se deu desde meados da década de 1910 até o início da década de 1940, período no 
qual Pixinguinha atua no circuito comercial da indústria do disco, nos programas de rádio e em locais de entretenimento da cidade do Rio de Janeiro, como também durante o período em que esteve em viagens nacionais $e$ internacionais realizadas com o grupo Os Oito Batutas.

Por outro lado, Pixinguinha foi influenciado por práticas musicais afrodescendentes como o batuque e a umbigada, entre outros tipos de expressões musicais coletivas. Alguns músicos descendentes das chamadas tias baianas participaram das práticas dos sambas surgidos no contexto da Casa da Tia Ciata. Dentre eles destacam-se João da Baiana, Donga e Pixinguinha, que ali praticavam o samba vindo da Bahia e renovado na cidade do Rio de Janeiro (MENEZES BASTOS, 2005; MOURA, 1983).

Nessa perspectiva destaca-se a atuação de Pixinguinha como o resultado de uma história de vida peculiar. $\bigcirc$ compositor conviveu desde a sua infância com figuras significativas no âmbito do choro praticado na passagem do século XIX para o início do século XX, época na qual se praticavam os ritmos advindos das danças de salão europeias. Cresceu em uma época de sedimentação dos gêneros musicais brasileiros como o samba, o choro e a música de carnaval, praticada inicialmente como música instrumental para pequenas bandas de sopros. Por outro lado, absorveu influências da música internacional, não apenas por meio das orquestrações das jazz bands, presentes no Brasil desde 1917!, como também a partir dos acompanhamentos orquestrais da música americana cantada.

\section{Almirante e o programa radiofônico O Pessoal da Velha Guarda}

$\bigcirc$ programa $\bigcirc$ Pessoal da Velha Guarda, veiculado entre os anos de 1947 a 1952, pela Rádio Tupi do Rio de Janeiro, surge em um momento no qual alguns músicos, compositores e os pesquisadores musicais atuantes desde meados da década de 1940 se mobilizavam em defesa da música brasileira considera de "raiz", como ao repertório ligado ao folclore musical, e principalmente à música popular urbana dos seus primórdios.

\footnotetext{
I Segundo Ferreira (2005, p. 60), esse repertório de jazz bands americanas chegavam no Brasil através da música impressa e discos, e continuou influenciando a música brasileira até a década de 1940.
} 
Dentre os pesquisadores, músicos e compositores destacam-se Villa-Lobos, Pixinguinha, Luciano Gallet, Lúcio Rangel, Ary Vasconcelos, entre outros. Tal grupo buscava destacar não só a música popular urbana de qualidade, como também o folclore que para eles "estava na iminência de desaparecer, ante os avanços inevitáveis do progresso" (CONÇALVES, 2009, p. 179). Segundo Conçalves (lbid., p. 179), esses intelectuais, liderados por Renato de Almeida, fundaram o Movimento Folclórico Brasileiro, que segundo o autor inicia-se em 1947 e persiste até o ano de 1964.

Para Hobsbawm e Ranger, na introdução do livro A invenção das tradições, tais iniciativas são consideradas como:

Reações a situações novas que ou assumem a forma de referência a situações anteriores, ou estabelecem seu próprio passado através da repetição quase que obrigatória. É o contraste entre as constantes mudanças e inovações do mundo moderno e a tentativa de estruturar de maneira imutável e invariável ao menos alguns aspectos da vida social que torna a "invenção da tradição" um assunto tão interessante para os estudiosos da história contemporânea (HOBSBAWM; RANCER, 1997, p. 10).

Os autores apontam ainda para uma perspectiva, que seria "a utilização de elementos antigos na elaboração de novas tradições inventadas para fins bastante originais", a possibilidade de surgimento de uma "linguagem elaborada, composta de práticas e comunicações simbólicas" (lbid., p. 14). Tal tendência foi vivenciada por Pixinguinha, como também por toda a equipe de músicos, no processo de criação e execução de arranjos para o programa radiofônico $\bigcirc$ Pessoal da Velha Guarda?.

Como afirmado acima, esse grupo de artistas que incorporam as ideias de se preservar as raízes da música popular urbana do Brasil de períodos anteriores ao início da década de 1950 encontra em Almirante

2 A partir desse momento o programa $O$ Pessoal da Velha Guarda será abreviado como OPVG. 
um porta-voz dos seus anseios, apesar de que sua atuação diferisse das formas com as quais os membros desse grupo atuavam nessa batalha. Por estar vinculado às dinâmicas do rádio de entretenimento, Almirante utilizavase de estratégias ligadas ao mercado, como os concursos de músicas e a participação do ouvinte entre outros aspectos. Tal perspectiva não restringia o repertório veiculado no programa OPVG apenas à qualidade musical, mas também às cargas significativas das músicas junto ao seu público.

Ainda com relação à forma de abordagem do repertório musical por parte de Almirante, o pesquisador McCann considera como aspecto negativo o fato de o programa ter realizado uma "recomposição" de um contexto histórico anterior a partir das perspectivas e lógicas do mercado (MCCANN, 2004 apud BESSA, 2010). Por outro lado, destaca ainda um ponto positivo do programa OPVG, no qual "ao invés de simplesmente recriar o passado através de impressões, ele estaria resgatando-o ao vivo, trazendo os personagens reais de suas investigações ao palco (MCCANN, 2004, p. 162).

Almirante lançava músicas compostas por membros dos grupos musicais que atuavam no programa, como Pixinguinha, Benedito Lacerda, Jacob do Bandolim e Raul de Barros, entre outros. As interpretações de músicas instrumentais, tanto de compositores do princípio do choro quanto as compostas por músicos que atuavam no regional e na orquestra do programa, por um lado, apropriavam-se das estéticas ligadas ao princípio do choro no Brasil, como também se utilizavam de instrumentações e orquestrações originais para a época.

No contexto do programa radiofônico OPVG, Almirante priorizou não só o repertório ligado ao princípio do choro, mas também os sucessos musicais dos espetáculos de teatro musicado e as músicas populares dos carnavais do Rio de Janeiro, desde os tempos dos ranchos. Algumas dessas composições foram interpretadas com novos arranjos, cujas fontes originais concentravam-se em partituras editadas e nos discos de cera de 78 rpm, principalmente os lançados na fase mecânica de gravação no Brasil, do período de 1902 a 1927.

3 Termo utilizado por Oliveira (2008, p. 24), relacionado a iniciativas implementadas por Mário de Andrade no projeto modernista ligado à música por ele sugerido. 
Nessa perspectiva o programa recupera e traz o ouvinte de volta a um ambiente com o qual muitos se identificavam, fato comprovado pela ampla participação do público solicitando músicas. Os grupos musicais do programa, como também os instrumentistas ligados ao choro e cantores, executavam os arranjos e ambientações musicais com o intuito de realizar uma conexão do ouvinte com um passado musical da cidade do Rio de Janeiro.

Segundo Cumplowicz (2012, p. 17), nesse tipo de abordagem de repertório, a música se faz presente como uma "marca de pertencimento". "O meio sonoro é o signo de uma cultura particular". Essa cultura se expressa por meio de um percurso através do qual se observam "os usos e mensurações identitárias da música" (lbid., p. 18). Nesse sentido, em sintonia com os objetivos de Almirante, segundo Cumplowicz (Ibid., p. 18) "essas músicas trazem à cena os momentos, os lugares e as sociabilidades que contribuíram para a construção do indivíduo".

Essa ligação da música com um determinado espaço-tempo surge para Gumplowicz (lbid., p. 20) como "um signo revelatório de um grupo" e, portanto, como "um fator de constituição ou de consolidação de uma memória comum, reminiscências compartilhadas pelo indivíduo". Dessa forma, segundo o autor (ibid., p. 17), a música "indica um sentido de comunhäo" que se faz presente "pelas vozes que se elevam através dos cantos de marcha, hinos religiosos ou nacionais, canções militares e familiares passados de geração a geração".

\section{O repertório da orquestra popular do programa radiofônico OPVG}

Como afirmado acima, os direcionamentos de escolha do repertório do programa não se concentrou apenas nos aspectos relativos à qualidade musical. Diante dessa realidade, enumeramos no presente tópico alguns aspectos relativos aos critérios adotados por Almirante na construção do seu discurso durante o percurso do programa, a partir da atuação da orquestra popular do programa, dirigida por Pixinguinha.

Segundo Anna Paes (2012), o programa realizado no período de 1947 a 1952 teve cerca de duzentas exibições de meia-hora, as 
quais aconteciam duas vezes por semana. A partir dos fonogramas recuperados o programa OPVG, no caso vinte programas completos do acervo Collector's 4 , como também os registros sonoros feitos pelo bandolinista Jacob do Bandolim, foram catalogados um total de 269 títulos de músicas executadas no programa (PAES, 2012, p. 81 ).

A autora informa ainda que desse total, 75\% foi composto por músicas instrumentais, executadas pelos intérpretes acompanhados pelo Grupo dos Chorões, o qual era integrado por solistas como Benedito Lacerda (flauta) e Raul de Barros (trombone), de alguns convidados como Jacob do Bandolim e Altamiro Carrilho (flauta), e pelos músicos acompanhantes que integravam o regional, dentre eles, Horondino Silva, conhecido como Dino 7 cordas, Meira (violão), Gilson (pandeiro) e Pedro da Conceição (percussão). Em algumas peças atuavam como solistas os pianistas Lauro Araújo e Ernani Filho (lbid., 2012, p. 49). Parte desse percentual, cerca de $50 \%$ das músicas, era executado pela orquestra do programa.

Esses arranjos realizados por Pixinguinha para a orquestra popular do programa OPVG, do período de 1947 a 1952, foram lançados em duas séries de partituras, a Pixinguinha na pauta: 36 arranjos para 0 programa $O$ Pessoal da Velha Guarda (PAES LEME, 2010) e Pixinguinha: outras pautas: 44 arranjos para o programa $\bigcirc$ Pessoal da Velha Guarda (PAES LEME et al., 2014). Tais edições foram organizadas por Bia Paes Leme, coordenadora de música do Instituto Moreira Salles no Rio Janeiro, como também pelos músicos e arranjadores Pedro Aragão, Marcílio Lopes e Paulo Aragão, além de outros músicos.

\section{O repertório tradicional do princípio do choro}

Em termos musicais, as obras de compositores considerados como "canônicos" do princípio do gênero choro conservam as características relativas à forma-conteúdo musical que consolidou o gênero, o qual foi sistematizado por meio das composições dos compositores considerados por Vasconcelos (1984) como integrantes das três primeiras gerações do choro no Brasil.

4 Collector's Studios Ltda. Acervo em acetado de 20 programas $\bigcirc$ Pessoal da Velha Guarda (1947-1952), comercializado através do site <www.collectors.com.br>. Acesso em: 23 ago. 2014. 
Nas séries de partituras citadas acima (PAES LEME, 2010; PAES LEME et al., 2014), compostas de arranjos realizados por Pixinguinha para a orquestra popular do programa OPVG, constam 25 músicas de autoria de 16 compositores consagrados do princípio do choro (Quadro 1). Dentre elas destacam-se composições de Ernesto Nazareth, como o tango "Ferramenta", e a polca "Flor do Abacate", de Álvaro Sandim, entre outras, ambas compostas e registradas em disco de cera de 78 rpm, em gravações do início do século XX.

Quadro 1: Repertório de compositores do princípio do choro no programa OPVG.

\begin{tabular}{|l|l|l|}
\hline \multicolumn{1}{|c|}{ Música } & \multicolumn{1}{|c|}{ Gênero } & \multicolumn{1}{c|}{ Compositor } \\
\hline Batuque & & Henrique Alves de Mesquita \\
\hline Caúcho (corta-jaca) & tango-choro & Chiquinha Conzaga \\
\hline $\begin{array}{l}\text { Para a cera do } \\
\text { santíssimo }\end{array}$ & canzoneta & $\begin{array}{l}\text { Chiquinha Conzaga e Artur } \\
\text { Azevedo }\end{array}$ \\
\hline Água do vintém & tango & Chiquinha Conzaga \\
\hline Passinho de moça & schottisch & Henrique Dourado \\
\hline Odalisca & polca & Felisberto Marques \\
\hline Hilda (teu beijo) & polca-choro & Mario Álvares da Conceição \\
\hline Helena & valsa & Mario Álvares da Conceição \\
\hline Sertanejo & tango & Mario Álvares da Conceição \\
\hline $\begin{array}{l}\text { Meu casamento (olhos } \\
\text { de veludo) }\end{array}$ & schottisch & Pedro Caldino \\
\hline Jocosa & polca-choro & Pedro Caldino \\
\hline Flor do Abacate & polca & Álvaro Sandim \\
\hline Ferrementa & tango-fado & Ernesto Nazareth \\
\hline Turuna & tango & Ernesto Nazareth \\
\hline Dengoso & maxixe & Ernesto Nazareth \\
\hline Corroca & polca-choro & Luís de Souza \\
\hline Implorando & schottisch & Anacleto de Medeiros \\
\hline Os boêmios & tango & Anacleto de Medeiros \\
\hline Cabeça de porco & polca & Anacleto de Medeiros \\
\hline Bebê & maxixe & Paulino Sacramento \\
\hline O morcego & polca & Irineu de Almeida \\
\hline
\end{tabular}


Quadro 1: Continuação.

\begin{tabular}{|l|l|l|}
\hline \multicolumn{1}{|c|}{ Música } & \multicolumn{1}{c|}{ Gênero } & \multicolumn{1}{c|}{ Compositor } \\
\hline Jacy & schottisch-gavota & Irineu de Almeida \\
\hline Fantasia ao luar & schottisch & Albertino Pimentel \\
\hline Soluçando & choro & Candinho do Trombone \\
\hline Maxixe de ferro & maxixe & José Nunes \\
\hline
\end{tabular}

Fonte: Vianna (1955, 1957), Paes Leme (20 10) e Paes Leme et al. (20 I 4).

Além de tornar-se um clássico do repertório do choro, a polca "Flor do Abacate" integrou o repertório de músicas brasileiras citadas no balé O boi no telhado , de Darius Milhaud, com o argumento escrito por Jean Cocteau. $O$ grande rondó que compõe $O$ boi no telhado foi composto a partir de um processo composicional por justaposição (politonal), por meio de colagem de melodias de compositores brasileiros editadas em partituras, colecionadas pelo compositor francês no período em que morou na cidade do Rio de Janeiro, entre 1917 e 1918 (LACO, 2012).

O tango "Ferramenta" de Ernesto Nazareth, composto em 1905 (VASCONCELOS, 1964, p. 89) e o tango "Gaúcho (corta-jaca)" de Chiquinha Conzaga, entre outras, presentes no repertório executado pela orquestra popular do programa OPVG, também integraram o balé O boi no telhado, de Darius Milhaud (LACO, op. cit., p. 290-297).

A música que deu título a esse balé foi lançada no carnaval do Rio de Janeiro em 1918 e é de autoria de José Monteiro. Em 1922, ele teria integrado o grupo Les Batutes, em sua temporada em Paris (FLÉCHET, 2012). Segundo Fléchet (Ibid., p. 95), O boi no telhado, além de tornar-se o nome de um bar, local de encontro de intelectuais e músicos franceses na década de 1920, gerou o surgimento de uma expressão ligada ao contexto dos músicos de jazz em Paris. Para esses músicos, as gírias faire le boeuf (literalmente "fazer o boi") e taper le boeuf ("pegar o boi") é uma forma de se descrever o ambiente de uma sessão musical improvisada na França, desde o final da Segunda Guerra. Segundo a autora, "o boeuf tornou-se sinônimo de jam session para os músicos de jazz, e de "canja" no contexto brasileiro" (Ibid., 20 I2, p. 95).

5 Título original em francês: Le boeuf sur le toît. 
Por fim, dentre o repertório de compositores do princípio do choro presentes no programa OPVG, destacam-se algumas músicas que rememoram situações e lugares comuns ao universo do carioca do final do século XIX e início do século XX. Dentre elas destacam-se "Água do vintém" de Chiquinha Conzaga e "Cabeça de porco" de Anacleto de Medeiros. Essas músicas retratam situações pitorescas, como também lugares talvez já destruídos na época, como a casa de cômodos da Rua Riachuelo no Rio de Janeiro, que inspirou a polca "Cabeça de porco". Ambas as músicas tiveram suas histórias narradas por Almirante, a cada execução no programab.

\section{As composições de Pixinguinha}

Segundo Anna Paes (2012, p. 8 1-82), do total de 269 músicas que integraram os programas e áudios preservados, cerca de $20 \%$ delas são de autoria de Pixinguinha. Desse percentual, a metade dessas músicas relativas a essa porcentagem (25 músicas) foram interpretadas com arranjos de Pixinguinha para a orquestra do programa OPVG (Quadro 2). Dentre essas músicas de autoria de Pixinguinha, nove foram feitas em parcerias, com Benedito Lacerda e Vinicius de Moraes, entre outros. As outras composições de Pixinguinha foram interpretadas no programa e gravadas em disco pela dupla Pixinguinha e Benedito Lacerda.

Quadro 2: Composiçōes de Pixinguinha no programa OPVC

\begin{tabular}{|l|l|l|}
\hline \multicolumn{1}{|c|}{ Composições Pixinguinha } & \multicolumn{1}{|c|}{ Gênero } & \multicolumn{1}{|c|}{ Parcerias } \\
\hline Esquecida & polca-marcha & \\
\hline $\begin{array}{l}\text { Concerto para bateria } \\
\text { pamba de } \\
\text { partido-alto }\end{array}$ & polca-marcha & \\
\hline $\begin{array}{l}\text { Assim é que é (estou } \\
\text { voltando) }\end{array}$ & polca-marcha & $\begin{array}{l}\text { Pixinguinha, João Pernambuco e } \\
\text { Donga (?) }\end{array}$ \\
\hline Vou andando & polca & $\begin{array}{l}\text { Pixinguinha, Donga e João da } \\
\text { Baiana }\end{array}$ \\
\hline $\begin{array}{l}\text { Conversa fiada (conversa } \\
\text { de crioulo) }\end{array}$ & samba-raiado & \\
\hline Tô fraco (vem cá, não vou) & $\begin{array}{l}\text { choro- } \\
\text {-humorístico }\end{array}$ & \\
\hline
\end{tabular}

continua...

6 Músicas executadas, respectivamente, nos programas 6 e 15 do Acervo Collector's. 
Quadro 2: Continuação.

\begin{tabular}{|l|l|l|}
\hline Pula-sapo & polca & \\
\hline Urubatan & tango & Pixinguinha e Benedito Lacerda \\
\hline Ainda me recordo & tango brasileiro & Pixinguinha e Benedito Lacerda \\
\hline Ele e eu & polca & Pixinguinha e Benedito Lacerda \\
\hline Querendo bem & valsa & Pixinguinha e Ciro Porto \\
\hline Rancho abandonado & valsa & $\begin{array}{l}\text { Pixinguinha e Candido das } \\
\text { Neves }\end{array}$ \\
\hline Quem é vocé & polca-choro & \\
\hline Parangolé & maxixe & \\
\hline Cercando frango & polca-ligeira & \\
\hline Tango I (número um) & tango & \\
\hline Paciente & choro & Pixinguinha e Daniel Santos \\
\hline Dando topada & polca & \\
\hline Minha vez & polca & \\
\hline Caprichoso & choro & \\
\hline Vem cá Vitú (adaptação) & polca-marcha & Domínio Público \\
\hline Desprezado & choro & \\
\hline Lamentos & & Pixinguinha e Vinicius de Moraes \\
\hline Carinhoso (arranjo sinfônico) & & Pixinguinha e João de Barro \\
\hline $\begin{array}{l}\text { Seule (Sol sob a lama - } \\
\text { filme) }\end{array}$ & & Pixinguinha e Vinicius de Moraes \\
\hline $\mathbf{2 5}$ músicas (Pixinguinha) & & 10 músicas com parceria \\
\hline 1 Domínio público & & \\
\hline
\end{tabular}

Fonte: Paes Leme (2010), Paes Leme et al. (2014) e Acervo Collector's.

Nas composições de Pixinguinha destacam-se ao menos três tendências de abordagens composicionais para as mesmas que estão associadas às estratégias de Almirante na condução do repertório de músicas presentes no programa OPVG.

Alguns desses arranjos foram influenciados pelo estilo de orquestração da música americana veiculada nos discos e rádios desde o final da década de 1910. Essas composições de cunho humorístico (1) ou imitativas de sons onomatopaicos (2), cujos títulos 
carregam uma carga simbólica ligada, geralmente, ao universo do carioca. Dentre essas composições destacam-se: "Urubatan", "Pulasapo", "Marreco quer água", “Conversa fiada”, "Cochichando”, “Dando topada", "Vou andando", “Cercando frango" e "Tô fraco".

A última tendência observada nas composições e arranjos de Pixinguinha para o programa OPVG são as composições mais ligadas à estética tradicional do princípio do choro (3), principalmente as polcas. Dentre elas destaca-se a polca "Assim é que é".

As músicas relacionadas abaixo, no Quadro 3, foram gravadas em período anterior ao programa OPVG e obtiveram novos arranjos criados por Pixinguinha para a orquestra popular do programa. Dentre elas destacam-se as polcas "Vem cá não vou", "Estou voltando" e "Polca marcha", rearranjados por Pixinguinha no programa OPVG sob os títulos: "Conversa fiada", "Assim é que é" e "Tô fraco".

Quadro3: Músicas de Pixinguinha anteriores ao programa OPVG

\begin{tabular}{|l|c|l|}
\hline \multicolumn{1}{|c|}{ Músicas } & Lançamento & \multicolumn{1}{c|}{ Grupo } \\
\hline Desprezado & 1928 & Orquestra Típica Pixinguinha -Donga \\
\hline Lamentos & 1928 & Orquestra Típica Pixinguinha -Donga \\
\hline Carinhoso & 1928 & Orquestra Típica Pixinguinha -Donga \\
\hline Tô fraco (vem cá não vou) & 1929 & Orquestra Vitor Brasileira \\
\hline Urubatan & 1929 & Orquestra Vitor Brasileira \\
\hline Rancho abandonado & 1930 & Albenzio Perone \\
\hline $\begin{array}{l}\text { A esquecida (polca } \\
\text { marcha) }\end{array}$ & 1930 & Orquestra Bruswick \\
\hline $\begin{array}{l}\text { Assim é que é (estou } \\
\text { voltando) }\end{array}$ & 1932 & Grupo da Guarda Velha \\
\hline Ainda me recordo & 1932 & Grupo da Guarda Velha \\
\hline $\begin{array}{l}\text { Conversa fiada (conversa } \\
\text { de crioulo) }\end{array}$ & 1932 & Grupo da Guarda Velha \\
\hline
\end{tabular}

Fonte: Santos et al. (1982) e site Pixinguinha 120 anos? $^{7}$

7 Disponivel em: <www.pixinguinha.com.br>. Acesso em: 20 nov. 2017. 
A polca "Assim é que é", apresentada no programa OPVG, com autoria apenas de Pixinguinha, foi gravada em 1932, com o título "Estou voltando". Segundo informação contida em Vasconcelos (1984)8 a polca "Estou voltando", composta de quatro partes (A, B, C e D), teria a sua terceira parte composta em parceria de Pixinguinha com Donga e João Pernambuco. Na interpretação e no arranjo para o programa OPVG, as quatro partes da polca são executadas, e a autoria consta como sendo de Pixinguinha.

mesmo acontece com o samba-raiado "Conversa fiada", presente no repertório do programa com esse título, e com a autoria creditada apenas a Pixinguinha. A gravação de 1929, sob o título "Conversa de crioulo", traz no seu encarte a parceria com Donga e João da Baiana.

O choro-humorístico "Tô fraco", presente no repertório do programa OPVG, foi gravado anteriormente, em 1932, sob o título de "Vem cá não vou". A polca "A esquecida", também apresentada no programa OPVG pela orquestra popular dirigida por Pixinguinha, também foi gravada em período anterior, em 1930, com o título de "Polca-marcha".

Por fim, na série de composições de Pixinguinha interpretada pela orquestra, algumas parecem ter sido compostas especialmente para serem apresentadas no programa radiofônico. Dentre elas destacamse: "Marreco quer água", "Cercando frango", "Concerto de bateira" e "Vou andando", dentre outras. Uma música de domínio público, "Vem cá Vitú", teve um arranjo e uma parceria creditados a Pixinguinha. Outras musicas, gravadas pela dupla Pixinguinha e Benedito Lacerda na mesma época, foram aproveitas e orquestradas por Pixinguinha. São elas: "Ainda me recordo", "Urubatan" e "Eu e ele".

A polca ligeira "Cercando frango", além de um exemplo musical de vertente humorística, reflete ainda o universo social do carioca.

8 Vasconcelos (1984) afirma que obteve tal informação em um texto de autoria de Roberto Moura, no encarte de um LP, de 1978, do grupo de choro Calo Preto, que registrou a polca "Estou voltando" em ritmo de choro-lento. Segundo Moura, citado por Vasconcelos (Ibid., p. 100), a partir de dados presentes em uma partitura original pertencente ao arquivo de Ligia Santos, a parceria com Donga e João Pernambuco encontrava-se escrita em tal manuscrito. 
Segundo dados constantes no livro-encarte da série de partituras Pixinguinha: outras pautas: 44 arranjos para o programa $\bigcirc$ Pessoal da Velha Guarda (PAES LEME et al., 2014), não foram preservadas gravações originais da orquestra popular do programa para a polca "Cercando frango".

Segundo informações colhidas pela pesquisadora Anna Paes, - comentário de Almirante durante a apresentação da polca ligeira "Cercando frango" no programa OPVG propicia uma dupla interpretação sobre a motivação que levou Pixinguinha à escolha desse título. Ou seria o drama do goleiro na hora do gol, ou a busca de um frango em um galinheiro. Para Almirante, citado por Paes Leme no encarte da série de partituras Pixinguinha: outras pautas: 44 arranjos para o programa $\bigcirc$ Pessoal da Velha Guarda (PAES LEME et al., 2014), "o ouvinte que tire a sua conclusão ao ouvir este arranjo de Pixinguinha".

A interpretação do arranjo por parte da Orquestra Pixinguinha na Pauta demonstra esse efeito de correr atrás de algo, por meio do desfile da melodia entre os diversos naipes da orquestra, gerando essa espécie de jogo entre os diferentes timbres no espaço sonoro da sala de concerto. Segundo Bia Paes Leme', através desses arranjos de cunho descritivos e humorísticos, Pixinguinha nos remete ao ambiente de um filme. "Os naipes conversam". Por meio de sua "criatividade melódica e harmônica" nos sentimos "planando". Pixinguinha consegue "fazer a música voar".

\section{As outras músicas do repertório musical do programa OPVG}

Por fim, destacam-se as músicas do repertório ligadas aos signos sonoros apontados por Almirante, como também pelos ouvintes do programa, como relativos ao universo sonoro do carioca dos tempos mais remotos à época do programa OPVG. Dos arranjos executados pela orquestra dirigida por Pixinguinha, para as músicas de compositores diversos constam um número de 38 músicas e de 42 compositores

9 Depoimento presente no documentário Pixinguinha: ao mestre com carinho, publicado em 13/01/2017 (TV BRASIL, 2017). Acesso em: 28 nov. 2017. 
(Quadro 4). A partir de dados coletados nos textos das publicações de Paes Leme (2010), Paes Leme et al. (2014), Severiano e Homem de Mello (2006), constatou-se que algumas dessas músicas, marcadas em negrito, foram sucesso de carnaval do período de 1872 a 1925.

Quadro 4: Outros compositores no repertório da orquestra do programa OPVG

\begin{tabular}{|l|l|l|}
\hline \multicolumn{1}{|c|}{ Outros compositores } & \multicolumn{1}{|c|}{ Gênero } & \multicolumn{1}{|c|}{ Compositor } \\
\hline Fecha a carranca & polca & Aristóteles de Magalhães Fleury \\
\hline "I. Morette" & polca & Cesare Bonafous \\
\hline Morro da Favela & polca & Passos, Bornel e Bernabé \\
\hline Que é da chave & polca-lundu & José Soares Barbosa \\
\hline $\begin{array}{l}\text { Partimos para Mato } \\
\text { Grosso }\end{array}$ & polca-marcha & Zeferino Orcadiz \\
\hline Buenos dias & valsa & Aurélio Cavalcanti \\
\hline Vale tudo & Partido alto & Jacob do Bandolim \\
\hline Tudo preto & maxixe & Júlio Casado \\
\hline A mulher do bode & polca & Oswaldo Cardoso de Menezes \\
\hline $\begin{array}{l}\text { Da Urca ao Pão de } \\
\text { Açúcar }\end{array}$ & polca & Amadeu Taborda \\
\hline Salve o Sol & schottisch & Eduardo Violão \\
\hline Ai, ai & polca & Valério Vieira \\
\hline Subindo ao Céu & valsa & Aristides Borges \\
\hline $\begin{array}{l}\text { Olá seu Nicolau quer } \\
\text { mingau }\end{array}$ & dobrado & Costa Junior \\
\hline La mattchiche & marcha & $\begin{array}{l}\text { Charles Borel-Clerc, Paul Emille } \\
\text { Briollet, Léo Felix Lelièvre }\end{array}$ \\
\hline $\begin{array}{l}\text { Os passarinhos da } \\
\text { carioca }\end{array}$ & marcha & Luiz Nunes Sampaio (Careca) \\
\hline Saudade de Ouro Preto & valsa & Balduino R. Do Nascimento \\
\hline $\begin{array}{l}\text { Passarinho do má (voz e } \\
\text { rrquestra) }\end{array}$ & samba & $\begin{array}{l}\text { Ato. Lopes do Amorim Diniz } \\
\text { (Duque) }\end{array}$ \\
\hline $\begin{array}{l}\text { At a Georgia camp } \\
\text { meeting }\end{array}$ & cake-walk & Frederick Allen “Kerry” Mills \\
\hline Capenga não forma & polca & J. C. Flores Horta (1840?) \\
\hline Carnaval duvidoso & choro & Adalberto de Azevedo (1896) \\
\hline Chegou! Chegou! & polca & Mazarino Lima (1870- 1920) \\
\hline
\end{tabular}


Quadro 3: Continuação.

\begin{tabular}{|l|l|l|}
\hline Cheirosa & polca & Gumercindo Amaral \\
\hline $\begin{array}{l}\text { Dengo-Dengo (coro e } \\
\text { orquestra) }\end{array}$ & polca-tango & $\begin{array}{l}\text { Emilia Duque Estrada de Farias } \\
\text { (1870?) }\end{array}$ \\
\hline $\begin{array}{l}\text { Fadinho de Sabina } \\
\text { (laranjas da Sabina) }\end{array}$ & tango & $\begin{array}{l}\text { Francisco de Carvalho (1870?) e } \\
\text { Artur Azevedo }\end{array}$ \\
\hline Kananga do Japão & polca-choro & Sinhô (1888) \\
\hline O chá da meia-noite & tango & $\begin{array}{l}\text { Manuel Pedro dos Santos } \\
\text { (Baiano) (1870) }\end{array}$ \\
\hline Oh! Arara & polca & Antonio Santos Bocot (1850?) \\
\hline Os tiros da vovó & polca & C.J (domínio público) \\
\hline Róseas Flores d'alvorada & modinha & Anônimo \\
\hline Saudações & polca & Otávio Dias Moreno (1880?) \\
\hline Siri tá no pau & polca-marcha & Miguel A. De Vasconcelos (1880?) \\
\hline Só se me deres um beijo & polca & $\begin{array}{l}\text { Júlio Augusto Pereira da Cunha } \\
\text { (1840?) }\end{array}$ \\
\hline Careca não vai à missa & polca & Manuel Joaquim Maria (1840) \\
\hline Alfredinho no Choro & choro & Alfredo C. Bricio \\
\hline A Cigana de Catumbi & maxixe & José Resende (1882) \\
\hline E me deixou saudades & choro & José Ramos \\
\hline Buliçoso & choro & Juvenal Peixoto \\
\hline Molengo & maxixe & Pedro Antonio da Silva \\
\hline TOTAL: 38 músicas & & 42 compositores \\
\hline
\end{tabular}

Fonte: Paes Leme (2010) e Paes Leme et al. (2014).

A polca-lundu "Que é da chave?", de José Soares Barbosa, é a mais antiga dessas músicas. Segundo Paes Leme (2010), ela foi muito conhecida no Rio de Janeiro em 1872, e, posteriormente, teve uma música composta em resposta a ela, na peça teatral $A$ filha de Maria Angu, a polca "Achou-se a chave", de Aníbal de Amaral. Tal fato foi narrado por Almirante durante o programa OPVG, que foi ao ar no dia 26 de novembro de $1947^{10}$.

10 Transcrições dos programas de rádio do Almirante, feitas por Alexandre Dias. Disponivel em: <https://goo.gl/pBEz5r>. Acesso em: 23 abr. 2014. 
Outras duas músicas interpretadas pela orquestra popular do programa OPVG, com arranjos de Pixinguinha, são o tango " $\bigcirc$ chá da meia noite", de autoria de Manuel Pedro dos Santos (Baiano), e a polca "Os tiros da vovó", de domínio público, são exemplos de músicas que se tornaram populares nas ruas da cidade do Rio de Janeiro, em período anterior ao início do processo de gravação mecânica no Brasil, em 1902.

Um dos primeiros sucessos do carnaval carioca foi a polca "Oh! Arara". Gravada em 1902 pela Banda da Casa Edison, integrou o repertório da orquestra do programa OPVG (HIME, 2002). Por fim, um dos últimos sucessos de carnaval relembrados no programa OPVG foi o maxixe "A cigana de Catumbi", de autoria de José Rezende, registrada em disco em 1925 pela Orquestra Cícero (FRANCESCHI, 2002), como também, do mesmo ano, destaca-se o sucesso "Os passarinhos da carioca", de Careca (SEVERIANO; HOMEM DE MELLO, 2006).

repertório veiculado no programa radiofônico OPVG contemplou todos os tipos de gêneros populares na música popular urbana da cidade do Rio de Janeiro, não faltando ainda alguns sucessos de músicas estrangeiras, entre elas, a polca "I. Morette", a marcha "La mattchiche" e o cake-walk "At a Georgia camp meeting".

É interessante se observar que, em período anterior ao registro sonoro no Brasil e nos anos seguintes, até o início da década de 1920, o sucesso das músicas se dava nas ruas, nas músicas apresentadas nos teatros de revista, no período do carnaval, como também por meio da circulação de partituras. Boa parte das músicas de compositores das primeiras gerações do choro tornavam-se populares através das partituras manuscritas. Já os primeiros tangos brasileiros de Ernesto Nazareth e Chiquinha Conzaga tornavam-se conhecidos por meio de partituras editadas. Essas composições eram amplamente divulgadas nas festas familiares dos diversos bairros da cidade do Rio de Janeiro, como também nas lojas que comercializavam partituras e instrumentos musicais, entre eles o piano (PAES, 2012).

\section{O movimento $O$ Pessoal da Velha Guarda}

Ao final do período de produção do programa, em 1952, Almirante lança a ideia, entre os próprios ouvintes, de registrar em 
discos o repertório da Orquestra da Velha Guarda, dirigida por Pixinguinha para o referido programa. Tal intuito concretiza-se com a formação, em 1954, do grupo O Pessoal da Velha Guarda, que teve a sua estreia realizada durante o IV Centenário de Fundação da cidade de São Paulo. Desse grupo participaram os principais personagens do samba derivado da comunidade de afrodescendentes das casas das tias baianas, como a Tia Ciata, e músicos ligados ao choro, entre eles o trio Pixinguinha, Donga e João da Baiana, os flautistas velhos e jovens como Alfredinho (flautim) e Benedito Lacerda (flauta).

Tal grupo de músicos e jornalistas vieram a São Paulo para participar do I Festival da Velha Guarda promovido pela Rádio Record, onde Almirante apresentava programas radiofônicos. Diante do grande sucesso das primeiras apresentações, a equipe foi convidada a participar da cerimônia de aniversário da cidade de São Paulo (CABRAL, 2005). Cabral cita ainda a reação do público e dos artistas diante o impacto que tal grupo causava. Segundo o autor, após a participação dos programas radiofônicos na Rádio Record de São Paulo, o grupo seguia para o Clube dos Artistas. Nesse local, em meio a intelectuais e artistas do Rio de Janeiro e de São Paulo, o grupo executou diversos choros e sambas. A cantora Inesita Barroso expressou seus sentimentos ao calor do momento com a seguinte frase: "Meu Deus! Parece um sonho!"|' (Ibid., p. 24 I).

O último dia do I Festival da Velha Guarda foi realizado para um público maior na Parque do Ibirapuera, e foi transmito, segundo Cabral (Ibid., p. 244) pelas ondas médias e curtas da Rádio Record e pela TV Record. Tal evento aconteceu entre os dias 23 a 25 de abril de 1954. A partir dessas imagens foi realizado o documentário de Thomas Farkas, cujo som foi acoplado às imagens na década de 1990. Durante o mês de maio do mesmo ano, Pixinguinha permaneceu em São Paulo para, juntamente com Almirante, lançar o programa OPVG, na Rádio Record.

1 Segundo Cabral (2005, p. 241), tal declaração da cantora Inesita Barroso foi publicada na coluna Meia-Noite do jornal Ultima Hora de São Paulo. 
Em 1955 acontece o II Festival da Velha Guarda em São Paulo e inicia-se a gravação no Rio de Janeiro da série de LPs do grupo ligado a Pixinguinha e $\bigcirc$ Pessoal da Velha Guarda, pela gravadora Sinter ${ }^{12}$.

\section{Considerações finais}

Como conclusão do presente artigo destaca-se a necessidade de, através de uma possível análise crítica do que foi ressaltado de positivo do movimento $\bigcirc$ Pessoal da Velha Guarda, revelar outras possibilidade de abordagens sobre o assunto. Para tanto, como apontado acima, através das citações de Vinci de Moraes e de McCann, torna-se possivel ao pesquisador mais atento analisar de forma mais adequada o possivel intuito de Almirante nesse processo. Para McCann (2004):

- Pessoal da Velha Guarda ficou marcado como um movimento revitalizante mais amplo e manteve a sua essência. $\bigcirc$ programa e o movimento marcaram o nascimento de uma nova fase de choro, tornando o gênero mais popular a nível nacional do que nunca antes e expandindo suas possibilidades musicais. Mas essas inovações foram escondidas por uma ênfase constante na tradição e na preservação das riquezas culturais da nação... O Pessoal da Velha Guarda incorporou perfeitamente uma transição importante na evolução do nacionalismo brasileiro. 0 exaltado patriotismo de "Aquarela do Brasil" e o Estado Novo perderam sua moeda. O Pessoal da Velha Guarda expressou um novo protecionismo, defensivo e ressentido de influência estrangeira (p. 162).

Segundo Lima (2014, p. 96) a partir de observações de McCann (2004), "o programa OPVG foi simultaneamente a melhor e a pior coisa que aconteceu ao choro: se por um lado reviveu o gênero, por outro o condenou a ficar em uma forma restrita". Por outro lado, essa espécie de moldura relacionada às práticas musicais do princípio do choro não

12 São eles: A Velha Guarda (1955); Carnaval da Velha Guarda (1955); Festival da Velha Guarda (1956); Cinco Companheiros - Pixinguinha e os chorões daquele tempo (1956); Assim é que é... Pixinguinha e sua banda em polcas, maxixes e choros (1957); Pixinguinha e sua banda em Carnaval de Násara (1957); e Marchas de João de Barro e Alberto Ribeiro, com Pixinguinha e sua banda (1957). 
só evidenciou a prática musical antiga como também abriu caminhos para a inserção de novas características musicais introduzidas por Pixinguinha nos arranjados da orquestra popular do referido programa.

Outro aspecto importante de se destacar, já apontado acima, foi a presença do repertório mais ligado ao choro do seu princípio, como também de composições de Pixinguinha e dos seus contemporâneos interpretadas no programa OPVG. Muitas dessas músicas fizeram-se presentes em discos do trombonista Raul de Barros, do flautista Altamiro Carrilho e, principalmente, do bandolinista Jacob do Bandolim (PAES, 20 12). Segundo Anna Paes (Ibid., p. 83), "a partir da análise da discografia de Jacob do Bandolim" foram contabilizadas cerca de 40 músicas do repertório do programa, registradas "ao longo da sua carreira".

Com relação aos critérios de cunho musicológico acerca da qualidade de boa parte desses arranjos de Pixinguinha para o programa OPVG, e a partir das audições das gravações originais presentes no site do Instituto Moreira Salles, conclui-se que muitos desses arranjos foram realizados sem o devido tempo de maturação devido ao curto período de intervalo entre duas apresentações do programa semanal. Por outro lado, essa fluidez e de certa forma a simplicidade dos arranjos permitiram a Pixinguinha uma plena realização da sua capacidade criativa como arranjador e compositor.

\section{Referências}

ARACÃO, Pedro. O Baú do Animal: Alexandre Gonçalves Pinto e o choro. Rio de Janeiro: Folha Seca, 2013.

BESSA, Virgínia de Almeida. A escuta singular de Pixinguinha: história e música popular do Brasil nos anos 1920 e 1930. São Paulo: Alameda, 2010. 1996.

CABRAL, Sérgio. A MPB na era do rádio. São Paulo: Moderna, 
No tempo de Almirante: uma história do rádio e da MPB. 2. ed. Rio de Janeiro: Lumiar, 2005.

FERREIRA, Cláudio Leal. $\bigcirc$ papel dos sopros nos arranjos da música popular brasileira. In: TAUBKIN, Myrian (Org). Um sopro de Brasil: Projeto Memória Brasileira. São Paulo: Câmara Brasileira do Livro, 2005. p. 56-64.

FLÉCHET, Anaïs. Um boi pode esconder outro: história e memória do Boeuf sur le Toit. In: LACO, Manoel Aranha Corrêa do. O boi no telhado: Darius Milhaud e a música brasileira no Modernismo francês. São Paulo: Instituto Moreira Salles, 2012. p. 93-126.

FONTENELE, Ana Lúcia. A música popular urbana do final do século XIX e início do século XX no Brasil e sua influência nos arranjos da fase madura da carreira de Pixinguinha. Resonancias, Santiago, v. 20, n. 39, p. 155-174, 2016.

FRANCESCHI, Humberto Moraes. A Casa Edison e seu tempo. Rio de Janeiro: Sarapuí, 2002.

GARCIA CANCLINI, Néstor. Culturas hibridas: estratégias para entrar e sair da modernidade. 4. ed. São Paulo: Edusp, 2015.

CONÇALVES, José Reginaldo Santos. Luis da Câmara Cascudo e o estudo das culturas populares no Brasil. In: BOTELHO, André; SCHWARCZ, Lilia Moritz (Orgs.). Um enigma chamado Brasil: 29 intérpretes e um país. São Paulo: Companhia das Letras, 2009. p. 174-183.

CUMPLOWICZ, Philippe. Les résonances de l'ombre: musique et identités de Wagner au jazz. Paris: Fayard, 2012.

HIME, Joana (Prod.). Memórias musicais. Rio de Janeiro: Biscoito Fino, 2002. 15 CDs.

HOBSBAUM, Eric; RANCER, Terence. A invenção das tradições. Trad. de Celina Cardim Cavalcante. 4. ed. São Paulo: Paz e Terra S/A, 1997. 
LACO, Manoel Aranha do. Darius Milhaud no Brasil. In: . boi no telhado: Darius Milhaud e a música brasileira no Modernismo francês. São Paulo: Instituto Moreira Salles, 2012. p. 15-83.

LIMA, Giuliana Souza de. Almirante, "a mais alta patente do rádio", e a construção da história da música popular brasileira (1938 a 1958). São Paulo: Alameda, 2014.

MCCANN, Bryan. Hello, hello Brazil: popular music in the making of modern Brasil. Durhan: Duke University Press, 2004.

MENEZES BASTOS, José Rafael de. Les Batutas, 1922: uma antropologia da noite parisiense. Revista Brasileira de Ciências Sociais, São Paulo, v. 20, n. 58, p. 177- 196, 2005.

MORAES, José Geraldo Vinci de. Entre a memória e a história da música popular. In: VINCI DE MORAES, José Geraldo; SALIBA, Elias Thomé (Orgs.). História e música no Brasil. São Paulo: Alameda Casa Editorial, 2010. p. 217-268.

MOURA, Roberto. Tia Ciata e a Pequena África no Rio de Janeiro. Rio de Janeiro: Funarte, 1983.

OLIVEIRA, Anna Paula de. Sobre os modos de administrar heranças: o samba no novo Programa Nacional de Patrimônio Imaterial. In: DINIZ, Julio César Valladas; NAVES, Santuza Cambraia; CIUMBELLI, Emerson. Leituras sobre música popular, reflexões sobre as sonoridades da cultura. Rio de Janeiro: 7Letras, 2008. p. 21-37.

PAES, Anna. Almirante e $O$ Pessoal da Velha Guarda: memória, história e identidade. 2012 . Dissertação (Mestrado em Música) - Centro de Letras e Artes, Unirio, Rio de Janeiro, 2012.

PAES LEME, Bia (Org.). Pixinguinha na pauta: 36 arranjos para o programa $\bigcirc$ Pessoal da Velha Guarda. São Paulo: Instituto Moreira Salles: Imprensa Oficial, 2010.

PAES LEME, Bia et al. Pixinguinha: outras pautas: 44 arranjos para o programa $\bigcirc$ Pessoal da Velha Guarda. São Paulo: Instituto Moreira Salles: Imprensa Oficial do Estado de São Paulo: Sesc, 2014. 
SANTOS, Alcino et al. Discografia brasileira 78 rpm - 1902-1964. Rio de Janeiro: Funarte, 1982. 5 v.

SEVERIANO, Jairo; HOMEM DE MELLO, Zuza. A canção no tempo: 85 anos de músicas brasileiras - vol. I: 190 1-1957. 6. ed. Rio de Janeiro: Editora 34, 2006.

VASCONCELOS, Ary. Panorama da música popular brasileira. Rio de Janeiro: Livraria Martins, 1964.

Carinhoso etc: história e inventário do choro. Rio de Janeiro: Cráfica do Livro, 1984.

VIANNA, Alfredo da Rocha (Pixinguinha). A Velha Guarda (LP). Rio de Janeiro: Sinter, 1955.

Assim é que é... Pixinguinha e Sua Banda em polcas, maxixes e choros (LP). Rio de Janeiro: Sinter, 1957.

\section{Sobre a autora}

Ana Lúcia Fontenele graduou-se em Música/Composição Musical pela Universidade de Brasilia e realizou mestrado em Música na Contemporaneidade pela Universidade Federal de Goiás. Desde 2009 atua como professora efetiva na Universidade Federal do Acre. Tem experiência na área de Artes, com ênfase em Música, atuando principalmente nos seguintes temas: música eletroacústica, composição musical e música popular. Em abril de 2018 defenderá a tese do doutorado em Música pelo Programa de Pós-Graduação em Música da Escola de Comunicação e Artes da Universidade de São Paulo, na linha de pesquisa Musicologia/Ełnomusicologia.

Recebido em 01/02/2018

Aprovado em 04/03/20 18 